\title{
Associations between overweight, obesity, health measures and need for recovery in office employees: a cross-sectional analysis
}

Robine E van der Starre ${ }^{1}$, Jennifer K Coffeng ${ }^{1,2}$, Ingrid JM Hendriksen ${ }^{2,3}$, Willem van Mechelen ${ }^{1,2}$ and Cécile RL Boot ${ }^{1,2^{*}}$

\begin{abstract}
Background: With both a high need for recovery (NFR) and overweight and obesity being a potential burden for organizations (e.g. productivity loss and sickness absence), the aim of this paper was to examine the associations between overweight and obesity and several other health measures and NFR in office workers.

Methods: Baseline data of 412 office employees participating in a randomised controlled trial aimed at improving NFR in office workers were used. Associations between self-reported BMl categories (normal body weight, overweight, obesity) and several other health measures (general health, mental health, sleep quality, stress and vitality) with NFR were examined. Unadjusted and adjusted linear regression analyses were performed and adjusted for age, education and job demands. In addition, we adjusted for general health in the association between overweight and obesity and NFR.

Results: A significant positive association was observed between stress and NFR ( $B=18.04,95 \% C l: 14.53-21.56)$. General health, mental health, sleep quality and vitality were negatively associated with NFR $(p<0.001)$. Analyses also showed a significant positive association between obesity and NFR ( $B=8.77,95 \% \mathrm{Cl}: 0.01-17.56)$, but not between overweight and NFR.
\end{abstract}

Conclusions: The findings suggest that self-reported stress is, and obesity may be, associated with a higher NFR. Additionally, the results imply that health measures that indicate a better health are associated with a lower NFR.

Trial registration: The trial is registered at the Dutch Trial Register (NTR) under trial registration number: NTR2553.

Keywords: Cross-sectional study, Need for recovery, Employees, Overweight, Obesity, Health measures

\section{Background}

With the world rapidly urbanizing, people's working conditions have changed significantly [1]. Figures from several countries indicate an increase in work stress and psychosocial job demands [2,3]. Over $40 \%$ of EU workers experience a high workload on a daily basis and in the Netherlands, this number even comes close to $60 \%[4,5]$. One of the most important factors influencing an employee's physical and mental condition is the degree to

\footnotetext{
*Correspondence: crl.boot@vumc.nl

'Department of Public and Occupational Health, EMGO + Institute for Health and Care Research, VU University Medical Center, Amsterdam, The

Netherlands

2Body@Work, Research Center Physical Activity, Work and Health, TNO-VUmc, Amsterdam, The Netherlands

Full list of author information is available at the end of the article
}

which employees are able to recover from fatigue and stress at work [6]. Need for recovery (NFR) represents the short-term effects of a day at work and is described as the need to recuperate and unwind from workinduced effort [6,7]. A high NFR can be seen as an early precursor for developing high blood pressure [8], sleeping problems [9] and fatigue [10] and is associated with subjective health complaints, future sickness absence and future cardiovascular disease [11]. Furthermore, employees with a high NFR are at an increased risk of developing occupational diseases such as burnout and musculoskeletal disorders [12].

Parallel to the increasing workload, the prevalence of overweight and obesity has increased rapidly during the last decades and has reached pandemic proportions

\section{Biomed Central}


worldwide [13,14]. In the Netherlands in 2012, estimates indicate a $31.9 \%$ and $9.8 \%$ overweight and obesity prevalence, respectively [15]. Overweight and obesity are associated with negative consequences at work, including decreased productivity, more frequent absenteeism and sick leave $[16,17]$. Obese employees are at a two to threefold higher risk of work disability compared to their nonobese peers [18] and obesity has been shown to be a predictor of long-term sick leave [19]. If obesity levels remain unchanged, the growing obesity-related health burden will have large economic consequences. These will include an increase in costs $[20,21]$, both direct (as overweight and obesity are major risk factors for certain chronic diseases, including cardiovascular diseases and different forms of cancer $[18,22,23])$ and indirect (costs related to absenteeism, loss of productivity and disability) [16,17].

Following this line, both a high NFR and overweight and obesity are a potential burden for organizations (e.g. productivity loss and sickness absence) $[11,18]$. However, no studies have been conducted to test whether there is an association between these two variables. Furthermore, as overweight and obese persons tend to report a poorer health than their normal body weight peers [24-26], it is of added value to examine the association between health measures and NFR. To the best of our knowledge, health measures and their association with NFR have not been investigated so far. Therefore, it is interesting to examine the association between subjective health measures, such as general health, mental health, sleep quality, stress and vitality, and NFR.

The aim of this paper is twofold; 1) to examine the association between overweight and obesity and NFR and, 2) to examine the association between health measures (general health, mental health, sleep quality, stress and vitality) and NFR. We hypothesize that both overweight and obesity are associated with a higher NFR compared to normal body weight and that health measures that indicate a better health will be associated with a lower NFR.

\section{Methods}

\section{Study sample \& recruitment}

In this study, data from the baseline measurement of the Be Active \& Relax "Vitality in Practice" (VIP) project were used [27]. This randomized controlled trial was set up to evaluate a physical activity and relaxation intervention aimed at improving NFR in office workers. In September 2011, all 1,182 office employees (> 18 years) of a single financial service provider received an invitation to participate in the project. Those on sick leave for more than four weeks were not eligible to participate. An off-line questionnaire was administered at baseline, including measures of NFR, daily physical activity, general health, mental health, sleep quality, stress and vitality. All data were self-reported. A total of 414 employees (response rate: 35\%) from 19 departments signed the informed consent form, after which 412 employees completed the baseline questionnaire (providing data on NFR) and were included in the Be Active \& Relax project. This study was approved by the Medical Ethics Committee of the VU University Medical Center Amsterdam. The development and design of the Be Active \& Relax project has been described in full detail elsewhere [27].

\section{Dependent variable}

In this study, need for recovery (NFR) was assessed using the Need for Recovery after Work scale of the Dutch version of the Questionnaire of the Experience and Evaluation of Work (Dutch abbreviation: VBBA). The used subscale of the VBBA, a questionnaire on the perception and judgement of work [28], consists of 11 dichotomous items (yes/no). These items represent short-term effects of a day at work, with questions like "I find it hard to relax at the end of a working day" and "When I get home, people should leave me alone for some time", which were coded ' 0 ' or ' 1 ' in such a way that higher scores are related to more complaints. The NFR scale was computed by summing up the scores of the 11 items, of those providing data for at least 8 of the 11 items. The NFR total score was standardised to a score ranging from $0-100$, based on the number of items with valid data. When three items are missing, the total score is expressed as percentage of the eight items, instead of the eleven items (the number of scored points was divided by the number of answered items and multiplied by 100). Higher scores indicate a higher NFR after work. Internal consistency of the scale was tested in this study and was found to be of good quality $(\alpha=0.85)$, which is comparable to previous studies on NFR $[28,29]$. Employees with percentage scores of 54.5 or higher (a cut-off point of six or more positive responses, as recommended by Broersen et al.) [30,31] were considered to have a high NFR, as previous research showed that they have a higher risk for developing psychological complaints than people with a percentage score below $54.5[28,30,32]$.

\section{Independent variables}

Overweight and obesity were investigated by calculating BMI as the body weight in Health Organization recommendations [33]. Body weight and body height were assessed by self-report. BMI was categorized into three categories: normal body weight (cut-off point: $<25 \mathrm{~kg} / \mathrm{m}^{2}$ ), overweight (cut-off point: $25-<30 \mathrm{~kg} / \mathrm{m}^{2}$ ), and obesity (cut-off point: $\geq 30 \mathrm{~kg} / \mathrm{m}^{2}$ ) [33]. Those participants (1.9\%) categorized as underweight $\left(<18.5 \mathrm{~kg} / \mathrm{m}^{2}\right)$ were included in the normal body weight category because the number of participants did not allow a separate category $(n=6)$. For the same reason, participants categorized as extremely obese $\left(\geq 35 \mathrm{~kg} / \mathrm{m}^{2}, \mathrm{n}=9\right)$, were included in the overweight 
category. Normal body weight was chosen as reference category in the analyses.

\section{Health measures}

The following health measures were investigated: general health, mental health, stress, sleep quality and vitality.

General health and mental health were measured by items of the Dutch validated version of the Rand-36 measure of health-related quality of life [34]. General health perceptions were measured by asking employees to give an indication on how they perceived their health on a 5-pointscale (bad, moderate, good, very good or excellent) and to indicate on four propositions (e.g. "I more easily fall ill than others") to which extent on a 5pointscale they "totally agreed" or "totally disagreed". To assess mental health, employees were asked to indicate how often they had felt nervous, down, calm/relaxed, depressed/gloomy and tired, during the past four weeks. In this study, the Rand-36 measure of health-related quality of life has shown satisfactory internal consistency $(\alpha=0.85)$ for the assessment of mental health and reasonable internal consistency $(\alpha=0.73)$ for the assessment of general health. The internal consistency found in this study for mental health is comparable to other studies and for general health is slightly lower than previous research [34]. Both the general and mental health scale were computed by summing up the scores of the 5 items (in those providing data for at least 3 of the 5 items). The general and mental health total scores are transformed to a 0-100 range (as percentage of maximum total score) and all items are averaged in the same scale together. When items are missing, the scale average is filled, assuming that the respondent would have answered this item in a similar way as the others. Certain items were transformed such that higher scores indicate a better health status.

To measure stress, the Dutch short form of the Perceived Stress Scale (PSS) was used [35]. Participants were asked to indicate on a 5-pointscale ("never" to "very often") how often they had had certain feelings during the last month (e.g. "In the last month, how often have you felt that you were unable to control the important things in your life?"). Items were coded in such a way that higher scores indicate a higher level of stress. PSS-4 is considered to be sound, but previous studies have found a rather low internal reliability $(\alpha=0.60)$ [35]. In this study, however, a satisfactory internal consistency was found $(\alpha=0.70)$.

Sleep quality was assessed by the Dutch Jenkins Sleep Problems Scale [36]. This scale contains four items, i.e., trouble falling asleep, trouble to continue sleeping, waking up feeling tired and worn out, and trouble staying awake during the day. Participants were asked to indicate how often they had experienced the four criteria mentioned above in the past month ('0 days' to'22-31 days'), coded in such a way that higher scores indicate a better sleep quality. In this study, a marginal satisfactory Cronbach's alpha value of 0.61 was found, which is comparable to previously found internal consistency for the same construct [36].

Vitality was assessed using a part of the Utrecht Work Engagement Scale (UWES) [37], which contains 6 items (e.g. "At my work, I feel myself bursting with energy") that had to be answered on a 7-pointscale ("never" to "always"). Answers were coded in a way that higher scores designate better vitality. In this study, vitality indicates a satisfactory internal consistency $(\alpha=0.82)$. Previous studies reported comparable or even lower internal consistency $(\alpha=0.68-0.80)[37,38]$.

\section{Potential confounders}

Sociodemographic variables, such as gender, marital status (married/cohabitating, in a relation, no cohabitating, single, divorced, widowed) and educational level were self-reported. Educational level was divided into lower education (no education, primary school, lower vocational education or lower secondary school), middle education (intermediate vocational education or intermediate/higher secondary education) and higher education (higher vocational education and university). Although all from one single service provider, a great diversity in job types was found among respondents. As the job types within the financial service provider are related to educational level, educational level was examined as a potential confounder as a proxy for job type/skill level. Age was calculated by extracting the self-reported date of birth from the date of completion of the questionnaire by participant.

Job demands were taken into account, as previous studies have identified job demands to be associated with NFR [39]. This work-related variable was assessed using the items "work fast", "work hard", "no excessive work", "enough time" and "conflicting demands" [40] (4-point scale from "strongly agree" to "strongly disagree") which are part of the validated Dutch version of the Job Content Questionnaire (JCQ). An acceptable Cronbach's alpha value was found in this study for job demands $(\alpha=0.79)$. This is consistent with previous studies in different countries, including the Netherlands [40].

General health, described previously, was included as potential confounder in the relationship between overweight and obesity and NFR. Literature shows that obesity and general health are related [41-43]. Obese persons, as compared to their normal weight peers, seem to be more likely to have adverse health outcomes, such as poor general health $[41,43]$. As general health and overweight/obesity seem to be associated, we aimed at investigating the independent association between overweight and obesity and NFR, by correcting for associations between general health and NFR. 


\section{Statistical procedures}

Descriptive analyses were performed to summarize the characteristics of the population using means and standard deviations or percentages. For the outcome variable (NFR), a square root transformation was formally applied as its distribution was positively skewed, due to the high number of respondents scoring the minimum score of NFR 0-20 (37.7\%). This percentage is consistent with other studies on NFR [12]. However, the square root transformation did not meaningfully improve the distribution and therefore no transformation of original values was applied, which is in line with research of de Croon et al. [12]. Univariate linear regression analyses were used to determine the associations with NFR, which was treated as a continuous outcome variable, and each independent variable.

Potential confounders were included in the adjusted analyses as confounders when the Beta coefficient of the independent variable changed at least $10 \%$ following addition of the potential confounder to the model. Furthermore, potential effect modification by age, gender and job demands was tested in the adjusted models. For each effect modifier, a linear regression model was fitted by crossing a predictor (overweight, obesity and health measures) and a modifier and adding this interaction term to the regression model. Thereby, the interaction between overweight/obesity and general health was examined by performing an analysis of variance (two-way ANOVA F-test). The level of significance was set at $\mathrm{p}<0.05$. Data were analysed using SPSS Version 20.0 (SPSS Inc., Chicago, IL, USA).

\section{Results}

\section{Study population}

The participating employees were on average 41.3 years old $(\mathrm{SD}=10.3)$, ranging from 19 to 63 years. Average BMI was $24.9(\mathrm{SD}=4.0)$ and most employees (58.5\%) were classified as having a normal body weight (BMI < $25 \mathrm{~kg} / \mathrm{m}^{2}$ ), 31\% was classified as overweight and $10.5 \%$ was classified as obese. For two participants, BMI could not be calculated because of missing data on body weight and/or height. The overall mean score of NFR in the total study population was $32.2(\mathrm{SD}=29.3)$ and a total of $22.8 \%$ showed a high need for recovery $(>54.5)$. The mean NFR for the normal body weight, overweight and obesity group were 32.4 $(\mathrm{SD}=27.6), 27.3(\mathrm{SD}=29.2)$ and $45.9(\mathrm{SD}=34.9)$ respectively. The population characteristics are summarized in Table 1.

\section{Overweight and obesity \& health measures}

Results of the unadjusted and adjusted linear regression models are shown in Table 2. Unadjusted analyses showed significant associations for all health measures (general health, mental health, sleep quality, stress and vitality) and obesity with NFR.
Adjusted analyses also showed significant association between health measures and NFR; significant positive associations $(\mathrm{p}<0.001)$ were observed between general health, mental health, sleep quality and vitality, and NFR. These results suggest that a better general health, better mental health, better sleep quality and a better vitality are all associated with a lower NFR. On the contrary, the significant negative association $(\mathrm{p}<0.001)$ between stress and NFR suggests that self-reported stress is associated with a higher NFR. After adjustment for confounding by age, educational level, job demands and general health, the significant positive association between obesity and NFR observed in the unadjusted analysis $(B=13.45,95 \%$ CI:4.03, 22.88, $\mathrm{p}=0.005)$ changed into a borderline significant positive association $(B=8.77,95 \%$ CI:0.01, 17.56, $p=$ $0.05)$, with normal body weight as the reference category. This finding points in the direction that obesity as compared to normal body weight may be associated with a higher NFR. No strong evidence was found to support an association between overweight and NFR, compared to normal weight. A significant interaction in the adjusted model was identified for job demands in the association between NFR and sleep quality $(B=-14.06,95 \% \mathrm{CI}$ : $-16.60,-11.51)$ and vitality $(B=-10.58,95 \%$ CI: -13.29 , -7.89). Subgroup analyses revealed different associations between sleep quality, vitality and NFR in employees with high job demands and employees with low job demands, with the strongest significant negative association found in employees with high job demands. No effect modification for age and gender was observed and no significant interaction between overweight/obesity and general health was found.

\section{Discussion}

The purpose of this study was to examine the association between overweight and obesity, health measures

\section{Table 1 Characteristics of the study population}

\begin{tabular}{lll}
\hline Characteristics & $\mathbf{n ~ ( \% )}$ & Mean (SD) \\
\hline Age (years) $(n=413)$ & $164(39.6)$ & \\
Female gender $(n=414)$ & $372(89.9)$ & \\
Dutch ethnicity $(n=413)$ & & $24.9(4.0)$ \\
BMI $(n=410)$ & $240(58.5)$ & \\
$\quad$ Normal body weight $\left(<25 \mathrm{~kg} / \mathrm{m}^{2}\right)$ & $127(31.0)$ & \\
$\quad$ Overweight $\left(25-29.9 \mathrm{~kg} / \mathrm{m}^{2}\right)$ & $43(10.5)$ & \\
$\quad$ Obese $\left(\geq 30 \mathrm{~kg} / \mathrm{m}^{2}\right)$ & $233(56.4)$ & \\
College/university education $(\mathrm{n}=413)$ & $312(75.3)$ & \\
Married/cohabitating $(\mathrm{n}=414)$ & & \\
Need for recovery $(\mathrm{NFR})(\mathrm{n}=412)$ & $318(77.2)$ & \\
$\quad$ Low $(<=54.5)$ & $94(22.8)$ & \\
High $(>54.5)$ &
\end{tabular}

BMI; Body Mass Index, n; number of cases, SD; standard deviation. 
Table 2 Unadjusted and adjusted linear regression models on need for recovery

\begin{tabular}{|c|c|c|c|c|c|c|}
\hline \multirow{3}{*}{ Exposure variable } & \multicolumn{6}{|c|}{ Need for recovery } \\
\hline & \multicolumn{2}{|c|}{ Unadjusted analysis } & \multirow[b]{2}{*}{ p-value } & \multicolumn{2}{|c|}{ Adjusted analysis $^{\mathrm{A}}$} & \multirow[b]{2}{*}{ p-value } \\
\hline & $\beta$ & $(95 \% \mathrm{Cl})$ & & $\beta$ & $(95 \% \mathrm{Cl})$ & \\
\hline \multicolumn{7}{|l|}{ BMI categories } \\
\hline Normal body weight $\left(<25 \mathrm{~kg} / \mathrm{m}^{2}\right)$ & \multicolumn{2}{|c|}{ reference } & \multicolumn{2}{|c|}{ reference } & \multicolumn{2}{|c|}{ reference } \\
\hline Overweight $\left(25-29.9 \mathrm{~kg} / \mathrm{m}^{2}\right)$ & -5.15 & $(-11.40,1.10)$ & 0.106 & $-3.55^{\mathrm{B}}$ & $(-9.43,2.34)$ & 0.237 \\
\hline Obesity $(\geq 30$ kg/m²) & 13.45 & $(4.03,22.88)$ & 0.005 & $8.77^{\mathrm{B}}$ & $(0.01,17.56)$ & 0.050 \\
\hline \multicolumn{7}{|l|}{ Health measures } \\
\hline General health & -0.61 & $(-0.78,-0.46)$ & $<0.001$ & -0.58 & $(-0.73,-0.44)$ & $<0.001$ \\
\hline Mental health & -1.03 & $(-1.19,-0.87)$ & $<0.001$ & -0.93 & $(-1.09,-0.76)$ & $<0.001$ \\
\hline Sleep quality & -16.15 & $(-18.75,-13.56)$ & $<0.001$ & $-14.06^{\mathrm{C}}$ & $(-16.60,-11.51)$ & $<0.001$ \\
\hline Stress & 20.26 & $(16.72,23.80)$ & $<0.001$ & 18.04 & $(14.53,21.56)$ & $<0.001$ \\
\hline Vitality & -10.84 & $(-13.73,-7.96)$ & $<0.001$ & $-10.58^{C}$ & $(-13.29,-7.89)$ & $<0.001$ \\
\hline
\end{tabular}

BMl; Body Mass Index, ${ }^{A}$ Adjusted for age, education and job demands, ${ }^{\mathrm{B}}$ Additionally adjusted for general health, ${ }^{\mathrm{C}}$ Adjusted for effect modification by job demands.

and need for recovery (NFR) in Dutch office employees. Our results showed that obesity and poor health status were associated with NFR, indicating that obesity and poor general health, poor mental health, poor sleep quality, self-reported high stress levels and poor vitality were associated with a high NFR. No significant associations were found between overweight and NFR in either unadjusted or adjusted models. After additionally adjusting for general health in the association between obesity and NFR, the positive association between obesity and NFR remained significant, although the association observed was attenuated. This indicates that obesity is independently associated with NFR, but that obesity is also partly associated with NFR as a result of poor underlying general health. Given the substantial reduction of the strength of the association after adjustment for confounding, this result has to be interpreted with caution.

Previous studies showed that both overweight and a high NFR are important factors in developing long-term health problems, sickness absence and productivity loss $[11,16,17]$. To date, there is a lack of evidence on the associations between overweight and obesity and NFR. In this study it was found that obesity, as compared to normal body weight, was associated with a high NFR. Since obesity and NFR are associated with subjective health complaints, future sickness absence and occupational diseases such as burnout and musculoskeletal disorders $[11,12,16,17,19]$, it is important to further explore this association and to determine its causality.

In contrast to our expectations, we did not find a significant association between overweight and a high NFR. A negative tendency - although non-significant - was observed, which suggests that overweight, as compared to normal body weight, is associated with a lower NFR in office employees. This opposite direction is in accordance with the results of a recently performed systematic review, which found that overweight, as compared to normal weight, was associated with a significantly lower all-cause mortality whereas obesity was associated with a significantly higher all-cause mortality [44]. A possible explanation for the difference in direction of the associations found can be the large number of employees with a BMI slightly above the $24.9 \mathrm{~kg} / \mathrm{m}^{2}$, which classifies them in the overweight instead of normal body weight group. This may underestimate the association between overweight and NFR.

As overweight and obese persons tend to report a poorer self-rated health than their normal body weight peers [24-26], the association between other health measures and NFR are also important to examine in addition. In this study, a significant positive association between stress and NFR was found, suggesting that high levels of self-reported stress are associated with a higher NFR. A limited number of studies examined incomplete recovery in association with health complaints and stress. These few studies found similar results, as they showed that poor recovery after work was significantly associated with worse health status $[9,12]$ and long-term stress [45]. Furthermore, significant negative associations were observed in this study between the remaining health measures and NFR, suggesting that a better general health, better mental health, better sleep quality and better vitality are associated with a lower NFR. The associations observed here are a novel finding, as previous studies did not examine associations between these health measures and NFR.

\section{Strengths and limitations}

To our knowledge, this is the first study in which the association between overweight and obesity and NFR was 
studied. Thereby, this is one of the first studies with a focus on the association between health measures and NFR.

A major strength of the present study is the large sample size, which provided sufficient statistical power to examine associations between overweight, obesity, health measures and NFR in office employees. Thereby, the response rate (35\%) was acceptable for studies within worksites. A meta-analysis (61 studies published in 2000 and 56 studies in 2005) showed that this percentage is consistent for studies within worksites [46].

In addition, the prevalence of normal body weight (including underweight), overweight and obesity are comparable to the prevalence in the total Dutch population (58.5\% classified as normal weight, $31 \%$ classified as overweight, $10.5 \%$ classified as obese in our study versus $58.3 \%$ normal weight, $31.9 \%$ overweight, $9.8 \%$ obese in the total Dutch population) [15], which makes our study population a representative population. However, when interpreting the results it is important to keep in mind that this study was performed among sedentary office employees. Thereby, those on sick leave for more than four weeks were not eligible to participate and therefore our findings are not generalizable to populations with a high absenteeism rate.

A major limitation of this study is its cross-sectional design. Within this design, no conclusions regarding the causal directions of the associations can be drawn. This implies that NFR could either be increased due to obesity, or that a high NFR could contribute to the development of obesity (i.e. too tired to prepare healthy meals and/or engage in regular physical activity). In addition, the question remains whether a high NFR after work is an antecedent or a consequence of poor health. Another issue concerns a possible misclassification of the measurement of overweight and obesity. The estimation of overweight and obesity in this population is not perfect as it is solely based on self-reported body height and body weight. Self-reports of weight and height produce under-estimates as both men and women tend to overestimate their height and underestimate their weight [18,47]. Nevertheless, several studies, among others a study in a Dutch overweight working population, showed that selfreported body weight and height are of satisfactory reliability for the assessment of overweight and obesity [48] and are valid for identifying relationships in epidemiological studies [19]. Additionally, all information on independent and dependent variables was obtained using self-reports. Even if the questionnaire was designed to minimize self-report bias in responses, some items may have been subject to this type of bias. Finally, as the aim of this study was exploratory, we did not correct our p-values for multiple testing by e.g., the Bonferroni correction [49]. As the p-values of the results we found were at least ten times smaller than 0.05, applying the Bonferroni correction would not have changed our results.

\section{Implications for practice and research}

Given that recovery from work is important to maintain good health and well-being [50], strategies to reduce the need for recovery are important. It is important to identify factors that are associated with a high NFR, as well as the causal relationship between associated variables. Understanding the associations may contribute to understanding, and eventually reversing high NFR among office employees. These findings can support in the development of intervention strategies by addressing the unique concerns of workers and aspects of the workplace. The associations observed in this study are an important concern also for public health policy, as overweight, obesity, poor health status and NFR have considerable implications for morbidity $[11,18]$. A next step is to examine the causality of the associations observed here to develop prevention and intervention measures, in order to reduce the NFR among office employees. Follow-up studies are also needed to explore eating behaviour and lifestyle-related factors which are probably important mediating factors in the relationship between overweight, obesity and a high NFR.

\section{Conclusion}

Our findings confirmed our hypotheses that obesity is associated with a high NFR and that good health is associated with a low NFR. The results should be interpreted with caution. Because of its cross-sectional design, no causal relations can be identified. Given that recovery from work is important to protect employees' health and well-being, policies to decrease the NFR are important. As our findings have potentially important health implications, it is urgent to further explore the causal relationships involved in the associations observed here. Future studies should therefore focus on these outcomes and examine the effects of obesity and health measures on NFR in intervention trials.

\section{Abbreviations \\ NFR: Need for recovery; BMI: Body mass index.}

\section{Competing interests}

The authors declare that they have no competing interests.

\section{Authors' contributions}

REvdS wrote the first draft of the manuscript. JKC, IJMH, WVM and CRLB provided intellectual input and had a role in supervision. All authors have read and approved the final manuscript.

\section{Acknowledgements}

We like to thank all the participants for their time and collaboration. This project is part of the "Vitality in Practice" research program, which is financed by Fonds Nuts Ohra (Nuts Ohra Foundation). The trial is registered at the Dutch Trial Register (NTR) under trial registration number: NTR2553. 


\section{Author details}

'Department of Public and Occupational Health, EMGO + Institute for Health and Care Research, VU University Medical Center, Amsterdam, The Netherlands. ${ }^{2 B o d y @ W o r k, ~ R e s e a r c h ~ C e n t e r ~ P h y s i c a l ~ A c t i v i t y, ~ W o r k ~ a n d ~}$ Health, TNO-VUmc, Amsterdam, The Netherlands. ${ }^{3}$ TNO (Expert Center Life Style), Leiden, The Netherlands.

Received: 20 March 2013 Accepted: 16 December 2013

Published: 20 December 2013

\section{References}

1. Goston JL, Caiaffa WT, De Souza Andrade AC, Vlahov D: Health behaviors and occupational stress of Brazilian civil servants living in an urban center. Am J Ind Med 2013, 56(1):49-57.

2. Van Veldhoven MJPM, Sluiter JK: Work-related recovery opportunities: testing scale properties and validity in relation to health. Int Arch Occup Environ Health 2009, 82:1065-1075.

3. Kouvonen A, Kivimäki M, Cox SJ, Cox T, Vahtera J: Relationship between work stress and body mass index among 45,810 female and male employees. Psychosom Med 2005, 67:577-583.

4. Sluiter JK, De Croon EM, Meijman TF, Frings-Dresen MHW: Need for recovery from work related fatigue and its role in the development and prediction of subjective health complaints. Occup Environ Med 2003, 60:i62-i70.

5. Schaufeli WB, Kompier MAJ: Managing job stress in the Netherlands. Int Stress Manag 2001, 8:15-34.

6. Jansen NWH, Kant I, Van den Brandt PA: Need for recovery in the working population: description and associations with fatigue and psychological distress. Int J Behav Med 2002, 9(4):322-340.

7. Van Veldhoven M: Need for recovery after work. An overview of construct, measurement and research. In Occupational health psychology European perspectives on research, education and practice. Edited by Houdmont JLS. Nottingham: Nottingham University Press; 2008.

8. Stewart JC, Janicki DL, Kamarck TW: Cardiovascular reactivity to an recovery from psychological challenge as predictors of 3-years change in blood pressure. Health Psychol 2006, 25:111-118.

9. Sluiter JK, Van der Beek AJ, Frings-Dresen MHW: The influence of work characteristics on the need for recovery and experienced health: a study on coach drivers. Ergonomics 1999, 42:573-583.

10. Geurts SAE, Sonnentag S: Recovery as an explanatory mechanism in the relation between acute stress reactions and chronic health impairment. J Work Environ Health 2006, 32:482-492.

11. Van der Hulst M, Van Veldhoven M, Beckers D: Overtime and need for recovery in relation to job demands and job control. J Occup Health 2006, 48:11-19.

12. De Croon EM, Sluiter JK, Frings-Dresen MHW: Psychometric properties of the need for recovery after work scale: test-retest reliability and sensitivity to detect change. Occup Environ Med 2006, 63:202-206.

13. Global prevalence of adult obesity. http://www.iaso.org/site media/ uploads/Prevalence_of_Adult_Obesity_April_2011_New.pdf

14. Obesity and overweight. http://www.who.int/mediacentre/factsheets/ fs311/en/index.html.

15. Leefstijl, preventief onderzoek; persoonskenmerken. http://statline.cbs.nl/ StatWeb/publication/?DM $=$ SLNL\&PA $=81177$ ned $\& D 1=39-43 \& D 2=0-13,26$ $27,30,33-37 \& D 3=0 \& D 4=\mid \& W=T$

16. Jans MP, Van den Heuvel SG, Hildebrandt VH, Bongers PM: Overweight and obesity as predictors of absenteeism in the working population of the Netherlands. J Occup Environ Med 2007, 49(9):975-980.

17. Linde JA, Nygaard KE, MacLehose RF, Mitchell NR, Harnack LJ, Cousins JM, Graham DJ, Jeffery RW: HealthWorks: results of a multi-component group-randomized worksite environmental intervention trial for weight gain prevention. Int J Behav Nutr Phys Act 2012, 9:14.

18. Claessen H, Brenner $H$, Drath $C$, Arndt V: Repeated measures of body mass index and risk of health related outcomes. Eur J Epidemiol 2012, 27:215-224.

19. Robroek SJW, Van den Berg TIJ, Plat JF, Burdorf A: The role of obesity and lifestyle behaviours in a productive workforce. Occup Environ Med 2011, 68:134-139.

20. Barkin S, Heerman W, Warren M, Rennhoff C: Millennials and the world of work: the impact of obesity on health and productivity. J Bus Pyschol $2010,25: 239-245$
21. Aitken RJ, Allman-Farinelli MA, King LA, Bauman AE: Current and future costs of cancer, heart disease and stroke attributable to obesity in Australia-a comparison of two birth cohorts. Asia Pac J Clin Nutr 2009, 18:63-70.

22. Anandacoomarasamy $A$, Fransen M, March L: Obesity and the musculoskeletal system. Curr Opin Rheumatol 2009, 21:71-77.

23. Calle EE, Rodriguez C, Walker-Thurmond K, Thun MJ: Overweight, obesity, and mortality from cancer in a prospectively studied cohort of U.S. adults. N Engl J Med 2003, 348:1625-1638.

24. Marques-Vidal P, Ravasco P, Paccaud F: Differing trends in the association between obesity and self-reported health in Portugal and Switzerland. Data from national health surveys 1992-2007. BMC Public Health 2012, $12 \cdot 588$

25. Södergren M, Sundquist J, Johansson S, Sundquist K: Physical activity, exercise and self-rated health: a population-based study from Sweden. BMC Public Health 2008, 8:352.

26. Molarius A, Berglund K, Eriksson C, Lambe M, Nordström E, Eriksson HG, Feldman I: Socioeconomic conditions, lifestyle factors, and self-rated health among men and women in Sweden. Eur J Public Health 2007 17(2):125-133

27. Coffeng JK, Hendriksen IJM, Duijts SF, Proper KI, Van Mechelen W, Boot CRL: The development of the Be active \& relax 'vitality in Practice' (VIP) project and design of an RCT to reduce the need for recovery in office employees. BMC Public Health 2012, 12(1):592.

28. Van Veldhoven M, Broersen S: Measurement quality and validity of the "need for recovery scale". Occup Environ Med 2003, 60:i3-i9.

29. Kiss P, De Meester M, Kruse A, Chavée B, Braeckman L: Comparison between the first and second versions of the Copenhagen Psychosocia Questionnaire: psychosocial risk factors for a high need for recovery after work. Int Arch Occup Environ Health 2012 [Epub ahead of print]

30. Broersen JPJ, Fortuin RJ, Dijkstra M, Van Veldhoven J: Monitor occupational health and safety: indicators and limits (In Dutch). TBV 2004, 12:104-108.

31. Mohren $\mathrm{DCL}$, Jansen $\mathrm{NWH}$, Kant I: Need for recovery from work in relation to age: a prospective cohort study. Int Arch Occup Environ Health 2010 83:553-561

32. Verdonk P, Hooftman WE, Van Veldhoven MJPM, Boelens LRM, Koppes LL: Work-related fatigue: the specific case of highly educated women in the Netherlands. Int Arch Occup Environ Health 2010, 83:309-321.

33. World Health Organization: World Health Statistics. Geneva: World Health Organization (WHO); 2010.

34. Van der Zee Kl, Sanderman R: Het meten van de algemene gezondheidstoestand met de RAND-36, een handleiding. Groningen: Rijksuniversiteit Groningen, Noordelijk Centrum voor Gezondheidsvraagstukken; 1992.

35. Cohen S, Kamarcjk T, Mermelstein R: A global measure of perceived stress. J health Soc Behav 1983, 24:385-396.

36. Jenkins CD, Stanton BA, Niemcryk SJ, Rose RM: A scale for the estimation of sleep problems in clinical research. J Clin Epidemiol 1988, 41(4):313-321.

37. Schaufeli WB, Salanova M, Gonzalez-Roma V, Bakker AB: The measurement of engagement and burnout: a two sample confirmatory factor analytic approach. J Happiness Stud 2002, 3:71-92.

38. Schaufeli WB, Bakker AB: How changes in job demands and resources predict burnout, work engagement, and sickness absenteeism. J Organ Behav 2009, 30:893-917.

39. De Croon EM, Sluiter JK, Frings-Dresen MHW: Need for recovery after work predicts sickness absence A 2-year prospective cohort study in truck drivers. J Psychosom Res 2003, 55:331-339.

40. Karasek R, Brisson C, Kawakami N, Houtman I, Bongers P, Amick B: The Job content Questionnaire (JCQ): an instrument for internationally comparative assessments of psychosocial job characteristics. J Occup Health Psychol 1998, 3:322-355

41. Andreyeva T, Michaud P-C, Van Soest A: Obesity and health in Europeans aged 50 years and older. Public Health 2007, 121:497-509.

42. Ochner MH, Salvail FR, Ford ES, Ajani U: Obesity and self-reported general health, hawaii BRFSS: are polynesians at higher risk? Obesity 2008, 16:923-926.

43. Sturm R, Ringel JS, Andreyeva T: Increasing obesity rates and disability trends. Health Aff 2004, 23(2):199-205.

44. Flegal KM, Kit BK, Orpana H, Graubard Bl: Association of all-cause mortality with overweight and obesity using standard body mass index categories - a systematic review and meta analysis. JAMA 2013, 309(1):71-82. 
45. Kivimäki M, Leino-Arjas $P$, Kaila-Kangas L, Luukkonen $R$, Vahtera J, Elovainio $M$, Härmä $M$, Kirjonen J: Is incomplete recovery from work a risk marker of cardiovascular death? Prospective evidence from industrial employees. Psychosom Med 2006, 68:402-407.

46. Baruch $Y$, Holtom B: Survey response rate levels and trends in organizational research. Hum Relat 2008, 61(11):1139-1160.

47. Ostry AS, Radi S, Louie AM, LaMontagne AD: Psychosocial and other working conditions in relation to body mass index in a representative sample of Australian workers. BMC Public Health 2006, 6(53). http://www. ncbi.nlm.nih.gov/pmc/articles/PMC1409786/.

48. Dekker J, Van Wier M, Hendriksen I, Twisk J, Van Mechelen W: Accuracy of self-reported body weight, height and waist circumference in a Dutch overweight working population. BMC Med Res Methodol 2008, 28(8):69.

49. Perneger TV: What's wrong with Bonferroni adjustments. Br Med J 1998, 316(7139):1236-1238.

50. Sonnentag S: Work, recovery activities, and individual well-being: a diary study. J Occup Health Psychol 2001, 6:196-210.

doi:10.1186/1471-2458-13-1207

Cite this article as: van der Starre et al:: Associations between

overweight, obesity, health measures and need for recovery in office employees: a cross-sectional analysis. BMC Public Health 2013 13:1207.

\section{Submit your next manuscript to BioMed Central and take full advantage of:}

- Convenient online submission

- Thorough peer review

- No space constraints or color figure charges

- Immediate publication on acceptance

- Inclusion in PubMed, CAS, Scopus and Google Scholar

- Research which is freely available for redistribution 